\title{
Semantic as well as referential relevance facilitates the processing of referring expressions.
}

\author{
Catherine Davies* and Anna Richardson \\ School of Languages, Cultures, and Societies, University of Leeds, UK
}

*Corresponding author: School of Languages, Cultures and Societies, University of Leeds, LS2 9JT, UK.c.n.davies@leeds.ac.uk

This is the author-accepted version of a manuscript accepted by Journal of Pragmatics, 28/03/2021

\section{Acknowledgements}

We are grateful to Cecile De Cat, Judith Degen, and Ruth Filik for helpful discussions about this study, and to Frank Mollica and an anonymous reviewer for helpful comments on an earlier submission. Thanks to Gisela Tomé Lourido for her advice on statistical modelling, and to our experimental participants for giving their time. This work was originally developed as the second author's undergraduate dissertation (Richardson, 2017) and did not receive any specific grant from funding agencies in the public, commercial, or not-for-profit sectors.

\section{Author contributions}

CD: Conceptualisation, Methodology, Formal analysis, Data curation, Writing - Original Draft, Writing- Reviewing and Editing, Visualisation, Supervision. AR: Methodology, Investigation, Writing- Reviewing and Editing. 


\title{
Semantic as well as referential relevance facilitates the processing of referring expressions.
}

\begin{abstract}
A range of studies investigating how overspecified referring expressions (e.g., the stripy cup to describe a single cup) affect referent identification have found it to slow identification, speed it up, or yield no effect on processing speed. To date, these studies have all used adjectives that are semantically arbitrary within the sentential context.

In addition to the standard 'informativeness' design that manipulates the presence of contrast sets, we controlled the semantic relevance of adjectives in discourse to reveal whether overspecifying adjectives would affect processing when relevant to the context (fed the hungry rabbit) compared to when they are not (tickled the hungry rabbit). Using a self-paced reading paradigm with a sample of adult participants $(\mathrm{N}=31)$, we found that overspecified noun phrases were read more slowly than those that distinguished a member of a contrast set. Importantly, this penalty was mitigated when adjectives were semantically relevant.

Contrary to classical approaches, we show that modifiers do not necessarily presuppose a set, and that referential and semantic information is integrated rapidly in pragmatic processing. Our data support Fukumura and van Gompel's (2017) meaning-based redundancy hypothesis, which predicts that it is the specific semantic representation of the overspecifying adjective that determines whether a penalty is incurred, rather than generic Gricean expectations. We extend this account using a novel experimental design.
\end{abstract}

Keywords: Sentence processing; Referring expressions; Informativeness; Adjectives 


\section{Introduction}

When speakers refer to an object using a noun, they explicitly mention a property of the object when that property is relevant. This relevance stems from various sources. For example, when referring to one of a pair of dogs in the park, the speaker might add an adjective to disambiguate the dogs - the brown dog. Or, when a property is particularly salient, for example if a lone dog was a nonprototypical colour, e.g., the green dog. Or where the colour of the dog is crucial to the speaker's discourse goals, e.g., in professional breeding circles, the chocolate dog.

Although each of these reasons for modification has been evidenced in the reference production and comprehension literature, most of the empirical investigations to date have focused on the first: referential relevance - the provision of disambiguating information in multiple-object contexts. Online empirical evidence supports the intuitive phenomenon that in most cases, a member of a contrast set requires specifying detail for a referring expression to be informative and for reference to be resolved (Sedivy et al., 1999; Tanenhaus et al., 1995; see also Davies \& Katsos 2010; 2013 for offline evidence). If modification is omitted, the expression is underinformative or ambiguous, and reference is disrupted. More controversially, if modification is included when referring to a singleton object (where it is not strictly necessary), such expressions have been classified as overinformative, overspecified, or redundant.

Here we report a study that departs from the focus on referential relevance and investigates for the first time whether semantic relevance also justifies the inclusion of a modifier in referring expressions. We examine cases in which an apparently overinformative adjective is semantically relevant, i.e., when it provides an explanation for a described event. For example, Jess helped her colleague move the heavy table; Sam fed the hungry rabbit; Lou spat out the mouldy apple. In these cases, the adjective may be referentially overinformative in that it provides more information than is strictly necessary, but its semantic relevance gives it a predicative function, thus rendering it nonredundant. These kinds of utterances provide a useful test case for disentangling informativeness from redundancy.

For the last four decades, the empirical study of reference has been productive. Here we summarise the theoretical trajectory to date, focusing on the addressee's perspective. Following Grice's seminal work on The Cooperative Principle (1975), the traditional view has been that referential overspecification is non-optimal (Deutsch \& Pechmann, 1982; Pechmann, 1984; 1989). Within the Cooperative Principle, the maxim of quantity holds that speakers are expected to provide as much information as necessary but not more. For example, in a context containing a single cup, the unmodified expression the cup should be preferred to the spotty cup, lest a pragmatic inference be made. 
Experimental work supported this account. Using visual-world eyetracking to monitor addressee expectations about the amount of information required in a visual scene, Sedivy et al. (1999) showed that the presence of a contrast set leads addresses to rapidly infer that an adjective will refer to a member of that contrast set. Incrementally, participants inferred that tall would refer to a tall glass alongside a smaller glass, rather than to a tall jug on its own since it would be overinformative in the latter case (see also Grodner \& Sedivy, 2011; Heller, Grodner, \& Tanenhaus, 2008; Rubio-Fernandez, Mollica, \& Jara-Ettinger, 2021; Ryskin, Kurumada, \& Brown-Schmidt, 2019). Likewise, earlier work in syntactic ambiguity showed that referential context immediately affects parsing as comprehenders adopt analyses that avoid assumptions of redundancy (as well as ambiguity). In a reading time study, the introduction of a set (e.g., two different safes) led addressees to interpret the momentarily syntactically ambiguous blew open the safe with the... as introducing a noun modification (... with the diamonds) rather than a verb phrase (... with the dynamite), due to the assumption that sets and modifiers coexist (Altmann \& Steedman, 1988). This work was taken as evidence that modifiers presuppose a set of referents, with the corollary that when this presupposition is not supported, there will be a processing penalty as addressees revise their expectations online. These ideas were formalised as Referential Theory (Crain \& Steedmann, 1985; see also Tanenhaus et al., 1995). Importantly for the current study, this assumes that modifiers have only a disambiguating function, to the exclusion of a predicative one.

However, contrary to the Gricean expectation, experimental data has shown that speakers commonly overspecify when referring (Arts et al., 2011; Engelhardt et al., 2006, 2011; Maes, Arts, \& Noordman, 2004; Sedivy, 2003; van der Sluis \& Krahmer, 2007). This presents a puzzle for traditional referential theories since it suggests that modifiers do not always presuppose a set. An active debate has ensued as several studies investigated the online effects of overspecification. These have asked whether redundant utterances help or hinder comprehenders in choosing the intended referent, compared to minimally specified alternatives. Initial evidence was mixed. Some studies found that overspecified referring expressions 'impair comprehension' (Engelhardt et al., 2011), slow reading (Fukumura \& van Gompel, 2017), and elicit lower acceptability ratings in offline judgments (Davies \& Katsos, 2013). However, mounting evidence that overspecification (particularly colour adjectives) helps addressees identify the intended object more quickly (Arts et al., 2011; Engelhardt, Bailey, \& Ferreira, 2006; Mangold \& Pobel, 1988; Paraboni \& van Deemter, 2014; Paraboni et al., 2007; Rubio-Fernandez, 2016; under review; Sonnenschein \& Whitehurst, 1982), coupled with methodological objections to claims that overspecification impairs comprehension (Rubio-Fernandez, 2016), has led the field away from a narrow conception of overspecified reference as non-optimal.

Our study directly addresses a novel lexico-semantic account of referential processing proposed by Fukumura and van Gompel (2017). Using a series of reading experiments with eyetracking, they showed that redundant size-modification in sentences such as The small towel was soaking on the 
floor was read more slowly when it followed the context sentence There was one towel on the floor than when it followed a context sentence mentioning two towels. Because this effect was not replicated when stimulus sentences contained colour modifiers, Fukumura and van Gompel proposed a meaning-based redundancy hypothesis, in which referential processing is led by the specific semantic representation of the referring expression rather than generic Gricean expectations about optimal informativeness. They argue that because size modifiers require a comparison between two objects of different sizes, contexts which lack a size competitor impair comprehension through redundancy. Interestingly, using Fukumura and van Gompel's stimuli (translated into Chinese) and a noncumulative moving window paradigm, Wu and Ma (2020) did not replicate this penalty in processing redundant size modifiers. They nevertheless interpret their data to support the lexicosemantic account by attributing the results to readers accessing the contrast competitor in their mental models. The current study further tests the meaning-based redundancy hypothesis by asking whether the inclusion of a semantically relevant adjective would override the penalty induced by a referentially redundant adjective. Such evidence would support the view that referential processing is primarily led by the lexico-semantic representation of the referring expression.

The current study is timely as we face a paradigm shift in the theoretical characterisation of referential redundancy. In the last five years, the fields of cognitive science, artificial intelligence, and experimental pragmatics have begun to move away from seeing modified reference for singleton objects as inefficiently overinformative. Instead, redundancy is increasingly being seen as more rational (Degen et al., 2020) or communicatively efficient (Rubio-Fernandez, 2016; 2019; under review; Rubio-Fernandez et al., 2021); see Heller, 2020 for a recent review.

Working within the Rational Speech Act framework (Frank \& Goodman, 2012; Franke \& Jäger, 2016; Goodman \& Frank, 2016), the rational redundancy approach (Degen et al., 2020) incorporates a graded view of semantics, in which certain adjectives apply to a context better or worse than others, rather than being deterministically true or false in context. Speakers are seen to use adjectives strategically to pre-empt a possible ambiguity. Such adjectives may not be absolutely necessary for reference resolution, but they could safeguard against the addressee misunderstanding or investing too much processing effort into deducing the speaker's meaning. Concurrent to Degen and colleagues' work in physically-grounded reference, Rubio-Fernandez (2019; under review) has developed a view of redundancy as communicatively efficient and cooperative. By acknowledging a referential expression's discriminatory as well as its informational value, redundant colour adjectives are shown to be efficient in visual search.

Both of these novel lines of enquiry contrast radically to the standard Gricean view of overspecification. Instead, they continue in the tradition of Relevance Theory (Sperber \& Wilson, 1986/95), whose fundamental claim is that linguistically encoded meaning is inferentially enriched 
through the incorporation of contextual information until expectations of relevance are satisfied. Within this framework, the Cognitive Principle of Relevance states that human cognition is geared towards maximising relevance to exert a positive cognitive effect on the addressee, such as learning something new or strengthening or falsifying some previous knowledge. The second determinant is the Communicative Principle of Relevance, or processing effort. When there is considerable effort required in obtaining the intended meaning, the interpretation is less rewarding and consequently less relevant to the recipient. Thus, Relevance Theory claims that the greater an utterance's positive cognitive effect and the smaller its processing effort, the more relevant it will be. This will be a useful framework for interpreting our data on semantically relevant yet referentially redundant information. Theoretically, we hope to contribute to the emerging frameworks of rational redundancy (Degen et al., 2020) and communicative efficiency (Rubio-Fernandez, 2019; under review) in two ways: by highlighting the predicative or explanatory function of adjectives (in contrast to the traditional view that the main function of adjectives is to reduce ambiguity), and by providing data from the processing of written, discourse-based stimuli to add to existing visually-based datasets.

Studies that have tested theoretical accounts of overspecification have typically focused on colour and size adjectives that are semantically neutral with respect to the broader sentential context (and which have the advantage of being easy to control in visual displays). However, it is not yet known how referentially redundant (i.e., non ambiguity-reducing) adjectives affect processing when they a) have direct semantic and explanatory relevance to the discourse context, b) appear within a discourse rather than a visual context, c) represent a wider range of adjective semantics than size and colour, and d) do not occur alongside an ambiguous or underinformative experimental condition. Our study is novel in each of these aspects.

The current study departs from the presumption that modifiers presuppose a set. However, in addition to this kind of relevance, it also examines the effect of introducing an adjective that does not coincide with the presence of a set, yet is not informationally redundant. In this way, the design incorporates both referential and semantic relevance on adjective processing. First, an adjective is referentially relevant (or informative) if it uniquely identifies one of a previously mentioned contrast set, e.g., There were two apples, [...] the mouldy apple. In the multiple-referent context, the modified NP yields positive cognitive effects by uniquely identifying the referent. The modifier's presupposition of multiple entities is immediately satisfied, rendering the interpretation less effortful than in the one-referent context, which may induce a slowdown in reading times due to the redundancy of the modified noun. Second, an adjective is semantically relevant if it is causally related to the immediate context, for example the man spat out the mouldy apple. Under a relevancetheoretic account, contextual semantic relatedness provides the adjective with greater positive cognitive effects as it not only denotes a property of the noun, but also offers a relevant explanation for the preceding action. Where the adjective is not causally related to the sentential context, e.g., the 
man chewed the mouldy apple, no cognitive benefit is conferred, and reading time should increase as the participant searches for relevance.

We manipulated the referential and semantic relevance of an adjective within a noun phrase (within a sentence), and using self-paced reading paradigm, compared response times in each context. Our overarching research question asks whether relevant referential and semantic contexts facilitate processing. Our first hypothesis predicts that because the presence of a referential set will justify the inclusion of a disambiguating adjective, contrasting / relevant referential contexts will result in shorter reading times for modified noun phrases relative to singleton / less relevant, redundant referential contexts. This would replicate previous findings (Fukumura \& van Gompel, expts $1 \& 2$ ). Our second hypothesis predicts that because relevant semantic context from the verb (e.g., spat out) justifies the inclusion of a specific adjective (e.g., mouldy), these relevant semantic contexts will result in shorter reading times for modified noun phrases relative to less relevant contexts that are more neutral with respect to the verb (e.g., chewed). This would be a wholly novel finding. We also predict an additive effect, in which utterances which display both types of relevance and will be fastest of all to process, and those which display neither will be slowest.

\section{Method}

Participants carried out a self-paced reading task in which they controlled the presentation of segments of short vignettes.

\subsection{Participants}

32 participants were recruited from the student community at the authors' University. One was excluded after data collection because they answered 6 of the 10 comprehension questions incorrectly (the mean score from the rest of the sample was 92\%). This left the remaining sample at $\mathrm{n}=31$ (15 men and 16 women), aged 19-24 years old $(M=21, S D=1)$. This sample size allowed detection of a small effect size with a two-sided 5\% significance level and power of .75. None of the participants had studied psycholinguistics or pragmatics. All were native speakers of British English and had normal or corrected-to-normal vision and hearing. Each participated voluntarily. The experimental methodology was covered by a module block approval by the Faculty research ethics committee at the authors' institution.

\subsection{Design}

The experiment used a $2 \times 2$ design. Semantic relevance (relevant; irrelevant) and referential relevance (1-referent; 2-referents) were fully crossed, yielding four conditions. Both variables were 
manipulated within-participants and within-items. The outcome variables were reading time in two time windows: the noun phrase (critical window) and the following phrase (wrap-up).

\subsection{Materials}

The experiment consisted of 48 critical and 72 filler trials. A complete list of the stimuli can be found in the Appendix. For the critical items, 12 vignettes were created. Each vignette appeared in four versions corresponding to the four conditions, with the same noun phrase appearing in each version (see example in Table 1). Each vignette was made up of two sentences. The first sentence provided the referential context, either containing two referents of the same category (There were two spiders) or just one referent (There was a spider). In the two-referent context, the modified noun in the follow-up sentence satisfies presuppositions about multiple referents, whereas the one-referent context results in overspecification. The second sentence provided the semantic context, presenting a verb that was either semantically related to the following modified noun phrase (+sem) (she screamed at the scary spider) or was more neutral with little semantic association (-sem) (she stroked the scary spider). A natural-sounding wrap-up phrase concluded the second sentence.

Regarding the two time windows that were analysed, the noun phrase always consisted of an adjective and a noun and the wrap-up phrase was a prepositional phrase. Complete vignettes were between 15 and 24 words in length $(M=17.7, S D=2.3)$. Vignettes within the same quartet did not differ in length by more than one word. Because the verb was the only constituent that changed within each quartet (e.g., fed / tickled), its frequency within the same quartet was controlled to minimise differences in reading time. These differed by no more than 1.2 Zipf scale frequency (SUBTLEX-UK, 2020; van Heuven et al., 2014). Critical items were divided into five segments to enable self-paced reading.

Table 1: Example vignette from the critical items in four conditions. / indicates segmentation for selfpaced reading presentation.

\begin{tabular}{|l|l|l|}
\hline & Two referents & One referent \\
\hline \multirow{3}{*}{+ sem } & $\begin{array}{l}\text { There were two spiders / on Penny's book. / } \\
\text { She screamed at / the scary spider / for a long } \\
\text { time. }\end{array}$ & $\begin{array}{l}\text { There was a spider / on Penny's book. / } \\
\text { She screamed at / the scary spider / for a } \\
\text { long time. }\end{array}$ \\
\hline -sem & $\begin{array}{l}\text { There were two spiders / on Penny's book. / } \\
\text { She stroked / the scary spider / for a long } \\
\text { time. }\end{array}$ & $\begin{array}{l}\text { There was a spider / on Penny's book. / } \\
\text { She stroked / the scary spider / for a long } \\
\text { time. }\end{array}$ \\
\hline
\end{tabular}

The filler items were designed to reduce recognition of members of the critical vignette quartets. They also functioned as context for the comprehension questions. Filler vignettes comprised two short sentences (e.g., She drank coffee / every day. / Her doctor said / she should stop). None of the nouns 
or wrap-up phrases from the critical items were used in the fillers. Fillers ranged from three to five segments.

The 120 items were presented in a pseudorandomised order, preceded by seven practice items to accustom participants to using the space bar to control the presentation pace. These items were of similar length to the critical items but not of the same structure (see Appendix). Vignettes from the same quartet did not occur within nine trials of each other to ensure maximal distance. Trials were also block randomised to control for order effects, resulting in two lists. To ensure that the participants stayed focused and understood what they were reading, ten yes/no comprehension questions were inserted throughout the experimental block, and one within the practice block. These questions always related to the preceding filler trial, e.g., The plant was dying. It hadn't been watered in two weeks. Q: Was the plant recently watered? Four questions required a yes response and six required a no.

\subsection{Procedure}

All participants were tested in a single session that lasted approximately 15 minutes, at a quiet location at their convenience. The experiment was run on a laptop using SuperLab 4.5 presentation software (Cedrus Corporation, 2012). After giving their informed consent and receiving instructions, participants were told that they would be reading some sentences onscreen and that they were in control of the pace of their phrase-by-phrase presentation. They were instructed to press the space bar after they had read the phrase and when they were ready for the next phrase to replace it. They were told that there would be some yes/no questions relating to sentences they had just read, which they should respond to by pressing the $\mathrm{Y}$ or $\mathrm{N}$ key. They were asked to read at a natural pace and instructed not to memorise phrases, but to make sure they had fully understood the phrase before pressing the space bar. They were told that they would get a chance for breaks.

After pressing the space bar on the final phrase of each vignette, a fixation cross appeared at the centre of the screen for $1000 \mathrm{~ms}$ before the first segment of the following vignette appeared. Words appeared in black font at the centre of a white screen. Reading times for the noun phrase and wrap-up periods were recorded by the software, along with responses to the comprehension questions. A full debrief ended the procedure. None of the participants correctly guessed the pattern or purpose of the experiment. 


\section{Results}

418 datapoints were excluded from the original raw dataset $(14 \%)^{1} .412$ were more than two standard deviations above or below the mean RT for each item, and another six were below $100 \mathrm{~ms}$. Exclusions were distributed evenly between the 8 conditions $(M=52, S D=4$, range 46-56). Thus, 2558 of the original 2976 datapoints ( $31 \times 48$ trials in two time windows) went forward for analysis. Reading times were then log-transformed prior to statistical analysis to remove some of the skewness in the data (Baayen \& Milin, 2010). Data and code can be found at https://osf.io/dpuwa.

To examine the main effects and interaction of semantic and referential relevance on reading times during the noun phrase and the wrap-up windows, a linear mixed-effects model was fitted to the data for each time window separately. In addition to semantic relevance and number of referents (deviation-coded for deriving main effects), trial order (centred) was included in the model as a fixed effect, and participants and items were included as random effects. The maximum random structure supported by the data was determined through backward fitting (see Matuschek et al., 2017) and likelihood ratio tests. For both time windows, the random structure included random slopes for referents by participant, and random intercepts for both subjects and items. Model summaries can be found in Table 2. Statistical analysis was performed using mixed-effects regression as implemented in the package lme 4 v.1.1-23 (Bates et al., 2020) and the $p$-values were obtained using the package lmerTest v.3.1-2 (Kuznetsova, et al., 2020), both in R version 3.6.3 (R Core Team, 2020).

\footnotetext{
${ }^{1}$ We ran a supplementary LME analysis on a less conservatively trimmed dataset that excluded only the 6 data points $<100 \mathrm{~ms}$ and the 88 that were beyond the upper whiskers of the boxplotted original dataset $(=3 \%$ of the data). The results of this supplementary analysis did not differ from the reported analysis. Analysis scripts can be found at https://osf.io/dpuwa
} 


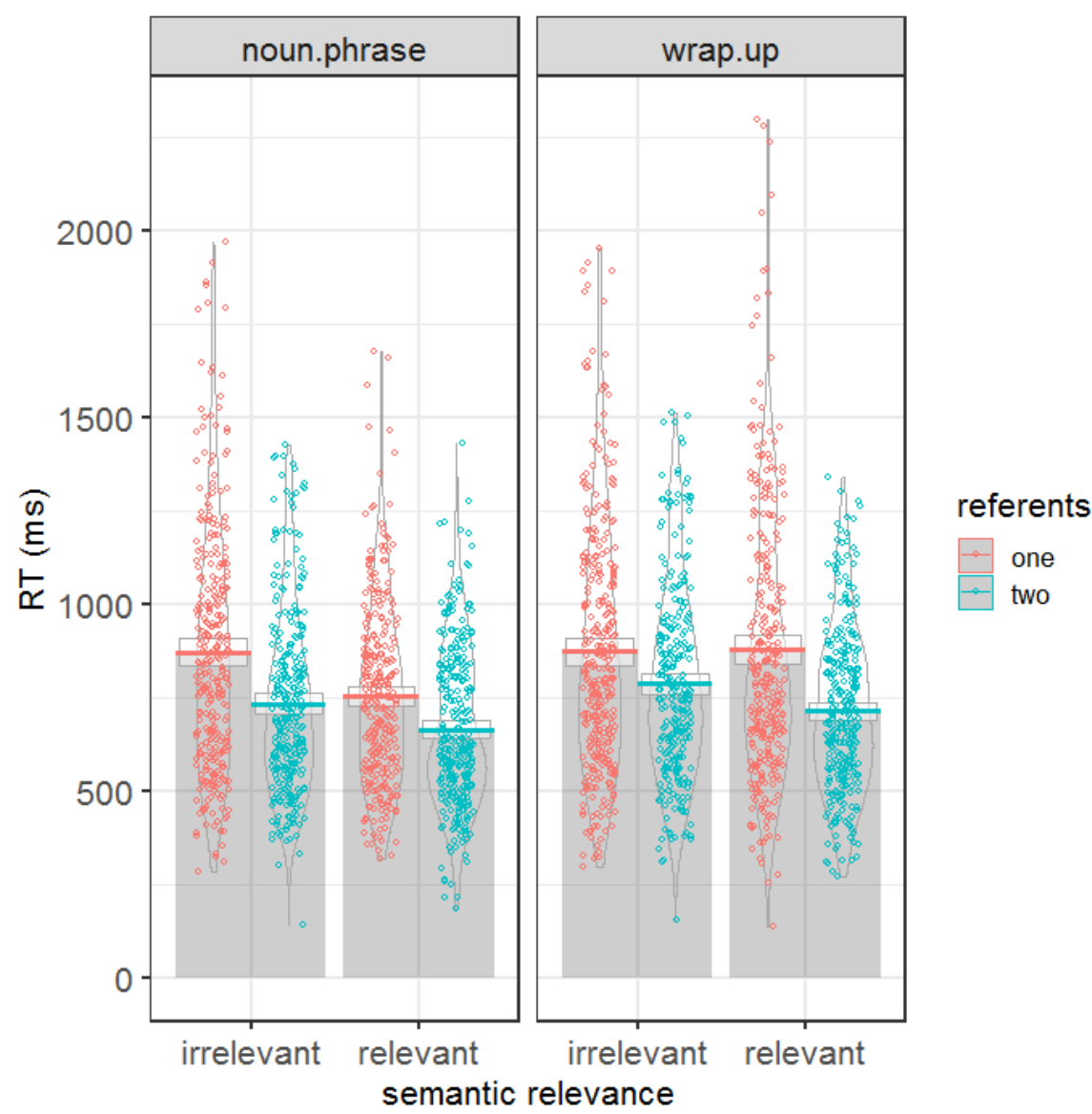

Figure 1. Reading times during the noun phrase and wrap-up windows, by semantic relevance of the adjective and number of referents in the vignette. Points show individual raw RTs, beans indicate density, shaded bars and horizontal lines indicate mean RTs, and the rectangle around the mean indicates $95 \%$ confidence interval.

Table 2. Model summaries for the effects of semantic relevance and number of referents on logtransformed reading times in two time windows.

\begin{tabular}{llllll}
\hline Noun Phrase & & & & & \\
\hline Random effects & Variance & $S D$ & Corr. & & \\
\hline Item (Intercept) & 0.02 & 0.15 & & & \\
Participant (Intercept) & 0.04 & 0.20 & & & \\
Referents (Slope) & 0.003 & 0.06 & 0.31 & & \\
Residual & 0.05 & 0.23 & & & \\
\hline Fixed effects & Estimate & $S E$ & $d f$ & $t$ value & $p$ value \\
\hline Intercept & 6.58 & 0.05 & 60.27 & 147.59 & $<.0001$ \\
Semantic relevance (relevant) & -0.11 & 0.05 & 47.64 & -2.31 & $0.026^{*}$ \\
Referents (two) & -0.13 & 0.05 & 50.87 & -2.81 & $0.007^{* *}$
\end{tabular}




\begin{tabular}{llllll} 
Trial order & 0.00 & 0.00 & 1237.83 & 1.33 & 0.18 \\
Semantic relevance x Referents & 0.02 & 0.09 & 47.72 & 0.23 & 0.82 \\
\hline Wrap-up & & & & & \\
\hline Random effects & Variance & $S D$ & Corr. & & \\
\hline Item (Intercept) & 0.04 & 0.2 & & & \\
Participant (Intercept) & 0.04 & 0.19 & & & \\
Referents (Slope) & 0.002 & 0.05 & 0.35 & & \\
Residual & 0.06 & 0.24 & & & \\
\hline Fixed effects & Estimate & $S E$ & $d f$ & $t$ value & p value \\
\hline Intercept & 6.67 & 0.05 & 75.62 & 140.97 & $<.0001$ \\
Semantic relevance (relevant) & -0.05 & 0.06 & 47.61 & -0.78 & 0.44 \\
Referents (two) & -0.13 & 0.06 & 49.31 & -2.07 & $0.04 *$ \\
Trial order & 0.00 & 0.00 & 1237.4 & -0.84 & 0.40 \\
Semantic relevance x Referents & -0.07 & 0.12 & 47.68 & -0.59 & 0.56 \\
\hline & & & & & \\
\hline
\end{tabular}

As the pirate plot in Figure 1 suggests and Table 2 confirms, there was a significant main effect of both semantic $(p<.05)$ and referential relevance $(p<.01)$ during the noun phrase window. In line with our predictions, they both resulted in shorter reading times than the corresponding non-relevant conditions. There was no interaction between the two variables.

In the wrap-up time window, there was a main effect of referential relevance $(p<.05)$, which resulted in shorter reading times. There was no effect of semantic relevance during this period, nor was there an interaction. There was no effect of trial order in either window, meaning that participants did not systematically speed up or slow down as the experiment proceeded.

\section{Discussion}

This study investigated the effect of referential and semantic relevance on the processing of noun phrases that were prenominally modified with a range of adjectives. Building on the literature from experimental and theoretical pragmatics as well as from sentence processing, we have replicated findings showing that multiple-referent contexts ease the processing of modified nouns (Sedivy et al., 1999; Tanenhaus et al., 1995). After sentences that introduced a singleton referent, modified phrases were read more slowly than when they followed sentences that introduced a contrast set. Thus we find an overspecification penalty, in line with Fukumura and van Gompel's (2017) reading study.

Crucially, we have shown for the first time that semantically relevant contexts ease the processing of 
modified nouns, even when the modification overspecifies (from an ambiguity-reduction perspective). After sentences that introduced an event that was causally related to the following adjective, the modified phrase was read more quickly than after sentences in which the event was neutral. Taken together, our findings suggest that referential and semantic information is integrated rapidly in pragmatic processing.

Our findings clearly support Fukumura and van Gompel's (2017) meaning-based redundancy / lexico-semantic hypothesis, which predicts that the specific semantic representation of the referentially overspecified adjective determines whether a penalty is incurred. In our slowest-read condition, which was non-relevant (or redundant) in both referential and semantic domains, comprehension was disrupted because the context failed to fulfil the presuppositions of referential contrast implied by the meaning of the modifier. Furthermore, it failed to activate a semantic link to justify the adjective's inclusion. Our referentially redundant but semantically relevant condition did not induce disruption to the same extent because despite the failure to fulfil referential presuppositions, the semantic context provides the processor with a reason to interpret the modifier, overriding the penalty induced by a referentially redundant adjective. Thus our data extends the meaning-based redundancy hypothesis to a wider range of adjectives, using a novel experimental design that does not include ambiguous sentences.

Our finding on referential relevance echoes early work showing that multiple-referent contexts facilitate a modifier reading when resolving temporarily ambiguous input (Altmann \& Steedman, 1988; Tanenhaus et al., 1995). We have demonstrated that in unambiguous discourse contexts, the existence of a set facilitates processing of a modifier, in line with studies of contrastive inference (Sedivy et al., 1999). In Relevance-Theoretic terms, by allowing the adjective to i) denote a property of the target referent, ii) satisfy the assumption that there are two entities of the same type in the context, and iii) implicitly convey the target object's uniqueness in possessing this property, positive cognitive effects were increased. Thus in the two-referent condition, cognitive effects are increased, effort is reduced, and relevance is maximised. These advantages do not occur in the one-referent condition, manifest as a relative slowdown in reading times.

Our data supports the psychological reality of the Relevance-Theoretic comprehension procedure. The theoretical claim that the greater accessibility of relevant input requires a less effortful search in interpretation is reflected here in the inverse relationship found between relevance and processing time. This online evidence builds on previous offline support for Relevance Theory (Sperber et al., 1995; van der Henst, Carles, \& Sperber, 2002), demonstrating the effect of relevance on the immediate incremental processing of utterances. To our knowledge, this is the first empirical investigation of relevance theory using referential sets. 
Our work extends the literature on referential redundancy in an important way: the slowdown elicited by this type of 'infelicity' can be significantly reduced by increasing the semantic relevance. We have shown that in single referent contexts, reading times are reduced when the 'overinformative' adjective offers a reason for the preceding action $(M=753 \mathrm{~ms}, S D=241$, vs. $M=872 \mathrm{~ms}, S D=326$ in the semantically irrelevant condition). Thus, semantic relevance mitigated the penalty of using an adjective to modify a singleton referent. This is an important finding as it shows that the use of a modifier does not necessarily presuppose a set, as predicted by standard Gricean or ReferentialTheoretic accounts. Instead, prior contextual manipulations at the semantic level adjust the relevance of the modified noun phrase. Increasing the causal relationship between the preceding action and the adjective induced greater positive cognitive effects. In these contexts, the adjective not only denotes a property of the entity but also offers a reason for the event. This evidence should now be used in future psycholinguistic research to expand the limited view of adjectives-as-ambiguity-reducers to a view that encompasses their descriptive function.

This interpretation is supported by theoretical frameworks of mental model construction in discourse processing (Johnson-Laird 1981; 1983). Comprehenders are said to inferentially construct mental models of the situation described by the linguistic input. These mental models provide much of the implicit meaning required by reference resolution (Garnham, 2001; Garnham \& Oakhill, 1990). To make sense of our stimulus sentences, participants made inferences using their world knowledge, such as the knowledge that spiders can cause people to scream, that hungry rabbits need feeding rather than tickling, or that humans are likely to spit out mouldy food. The semantically relevant sentences elaborated the readers' mental representation of the world, or confirmed an inference that would not be satisfied if the causal relationship was looser. Further, the preceding semantic context renders the related adjective more expected, more accessible, and subsequently less effortful to process. The increased reading times for sentences in less causally related semantic contexts is taken to reflect reduced cognitive effects, increased effort, and reduced relevance.

Mental models are also key to understanding the role of contrast sets in physically-grounded reference vs. discourse reference. In both kinds of context, referring expressions are conveyed linearly as either speech or writing. However, whereas in physically-grounded reference the referential context (including the presence or absence of contrast sets) comes from the visual display, in discourse-based reference the context comes from comprehenders' mental models, as our study employed (and central to $\mathrm{Wu} \& \mathrm{Ma}$ 's (2020) interpretations). Since mental models are more probabilistic, idiosyncratic, and arguably less stable than visual contexts, this might mean that contrastive inferences generated by the inclusion of an apparently redundant adjective are cancellable or more effortful to process in discourse reference than in physically-grounded reference. We would welcome future work that compares the nature (e.g. stability, timecourse, etc.) of contrastive inferences across contexts that are presented through discourse vs. visually. 
Our factorial design sought to disentangle informativeness from redundancy. We have shown that when an adjective is referentially overinformative, its semantic relevance renders it non-redundant. The latter relevance mitigates the penalty induced by the former. Recall that we predicted an additive effect of the two types of relevance, in which utterances which display both types of relevance would be fastest of all to process. Although the interaction between referential and semantic relevance was not significant, there was a supportive trend in the reading times, which were fastest in the tworeferent, semantically relevant condition $(M=666 \mathrm{~ms}, S D=211)$ and slowest in the two non-relevant conditions $(M=872 \mathrm{~ms}, S D=326)$. This 'double relevance' highlights the dual functions of adjectives: they describe as well as contrast referents (Davies, Lingwood, \& Arunachalam, 2020; Karmiloff-Smith, 1979). When they do both, processing is rapid. This is supported by Surprisal Theory (Levy, 2008) - a probabilistic account that predicts that a word's reading time is a function of its surprisal in a specific context. In line with this view, we have shown that doubly-relevant adjectives are less surprising, more expected, and quicker to read.

Our results have implications for the timecourse of information integration in referential processing. The significant effects of both referential and semantic relevance during the noun phrase suggest that this information is integrated rapidly and online. However, only the effect of referential relevance endured into the wrap-up window (as also found by Fukumura \& van Gompel, 2017, expts. 1 and 2), with a significant reduction in the mean reading time for relevant referential contexts regardless of semantic relevance. As Figure 1 suggests, semantic irrelevance is problematic only in the earlier stages of processing. During the noun phrase the one-referent penalty is greater when the adjective is irrelevant than when it is relevant, while during the wrap-up the one-referent penalty exists regardless of an adjective's semantic relevance. So why does the effect of an incongruity between the referential context and the use of modification persist, and the effect of a semantic incongruity disappear? It may be that referential incongruity is more disruptive to processing and thus more important to satisfy. The addressee continues to search for referential relevance beyond the noun phrase, whereas a neutral adjective can more easily be ignored. Although Fukumura and van Gompel (2017) did not manipulate semantic relevance, their eye movement data shows that participants launched late-stage regressive eye movements after reading redundant noun phrases, possibly to make inferences about reasons driving the redundancy, consistent with Grice (1975). In referentially relevant contexts, the immediate satisfaction of presuppositions about the existence of multiple referents maintains swift and efficient processing, whereas if presuppositions are left unfulfilled, the addressee continues to search for relevance. If an adjective appears to be unconnected to the prior event, the addressee simply accepts that its use is gratuitous. We welcome future studies that test this hypothesis to investigate the duration of the effect of relevance on processing. It would also be interesting to maximise the semantic relevance by providing a more elaborate discourse context to justify semantically relevant adjectives. 
One aspect of this study's novelty lies in its use of a wide range of adjectives. As reviewed in our introduction, much of the experimental research into contrastive inference has typically manipulated size, colour, and occasionally material properties. It finds that size and colour do not yield the same processing effects: size (a relative property) elicits comparison with other entities whereas colour (an absolute property) does not. This is evidenced in two ways. First, whereas size adjectives readily elicit contrastive inference, the effect is less stable with colour adjectives (Sedivy, 2003). Second, unlike size modifiers, the redundancy of colour modifier does not immediately slow down reading (Fukumura \& van Gompel, 2017, expts. 3 and 4). This is taken to indicate that initial referential processing is led by the lexico-semantic representation of the referring expression rather than Gricean expectations about optimal informativeness. Unlike Fukumura and van Gompel's experiments, our study did not control adjective semantics, though it did include relative (heavy, warm, weighty, large) as well as absolute (broken, noisy, hungry, mouldy, tasty, pretty, scary, bouncy) adjectives. A post-hoc analysis on the one-referent, semantically-irrelevant items (i.e., those with the largest penalty in the overall analysis) found no effect of adjective type on reading time in either the noun phrase (absolute adjectives $M=855 \mathrm{~ms}, S D=324$; relative adjectives $M=907 \mathrm{~ms}, S D=328, t=-1.39$, $\mathrm{df}=209, p=$ 0.2 ) or the wrap-up windows (absolutes $M=885 \mathrm{~ms}, S D=333$; relatives $M=891 \mathrm{~ms}, S D=348, t=-$ $0.15, \mathrm{df}=210, p=0.9)$. We would welcome higher-powered analyses of future studies that control this variable across a wider range of adjectives.

In our study, increasing the semantic relevance of the adjective renders it more expected, more accessible, and less effortful to process. As a specific follow-up study, we would welcome data that disentangles relevance and predictability effects. This could be tested using verbs are closely or more distantly semantically associated with the adjective, e.g., she ate / enjoyed the tasty food.

Our study is one of very few investigating redundancy through online sentence processing (see also $\mathrm{Wu} \& \mathrm{Ma}, 2020)$, relative to the large body of research using visual search. We would welcome an ongoing research programme that tests classic and emerging theories by taking a multimethodological approach to the study of redundancy. Our reading time measures would be usefully complemented by eyetracking studies that could track moment-to-moment processes, e.g., regressions to the verb to check meaning.

As we have discussed, our study has several implications for theory. We are hopeful that our discourse-based findings inform the development of rational redundancy models (Degen et al., 2020). To date, these approaches have focused on production or interpretation probabilities when referentially relevant (i.e., disambiguating) adjectives are included or excluded. Collaborative future work could incorporate cloze tasks that establish production probabilities for relevant adjectives within the noun phrase. This has the potential to expand the conception of informativeness as outlined above, and to refine the understanding of referential expectations. 


\section{References}

Altmann, G., and Steedman, M. (1988). Interaction with context during human sentence processing. Cognition, 30, 191 - 238.

Arts, A. Maes, A. Noordman, L. and Jansen, C. (2011). Overspecification facilitates object identification. Journal of Pragmatics. 43(1), 361-374.

Baayen, R. H., and Milin, P. (2010). Analyzing reaction times. International Journal of Psychological Research, 3.2, 12-28.

Bates, D., et al. (2020). lme4: Linear Mixed-Effects Models using 'Eigen' and S4. R package version 1.1-23. https://cran.r-project.org/web/packages/lme4/

Cedrus Corporation. (2012). SuperLab 4.5 (stimulus presentation software). San Pedro, CA.

Crain, S. and Steedman, M. (1985). On not being led up the garden path: The use of context by the psychological parser. In: Dowty, D. Kartunnen, L. and Zwicky, A. (eds). Natural language parsing. Cambridge: Cambridge University Press.

Davies, C. and Katsos, N. (2010). Over-informative children: production/comprehension asymmetry or tolerance to pragmatic violations? Lingua, 120, 1956-1972. doi:

10.1016/j.cognition.2011.02.015

Davies C. and Katsos N. (2013). Are speakers and listeners 'only moderately Gricean'? An empirical response to Engelhardt et al. (2006). Journal of Pragmatics, 49(1), 78-106. https://doi.org/10.1016/j.pragma.2013.01.004

Davies, C., Lingwood, J., and Arunachalam, S. (2020). Adjective forms and functions in British English child-directed speech. Journal of Child Language, 47(1), 159-185. doi: 10.1017/S0305000919000242

Degen, J., Hawkins, R.D., Graf, C., Kreiss, E., and Goodman, N.D. (2020). When redundancy is useful: A Bayesian approach to 'overinformative' referring expressions. Psychological Review. Advance online publication. https://doi.org/10.1037/rev0000186

Deutsch, W. and Pechmann, T. (1982). Social-interaction and the development of definite descriptions. Cognition, 11(2), 159-184.

Engelhardt, P. Demiral, B. and Ferreira, F. (2011). Over-specified referring expressions impair comprehension: An ERP study. Brain and Cognition. 77(2), 304-314.

Engelhardt, P., Bailey, K., and Ferreira, F. (2006). Do speakers and listeners observe the Gricean Maxim of Quantity? Journal of Memory and Language, 54, 554-573.

Frank, M. C., and Goodman, N. D. (2012). Predicting pragmatic reasoning in language games. Science, 336(6084), 998. https://doi.org/10.1126/science.1218633

Franke, M., \& Jäger, G. (2016). Probabilistic pragmatics, or why Bayes' rule is probably important for pragmatics. Zeitschrift fur Sprachwissenschaft, 35 (1), 3\{44. doi: 10.1515/zfs-2016-0002

Fukumura, K. and van Gompel, R. (2017). How do violations of Gricean maxims affect reading? Journal of Memory and Language, 95, 1-18.

Garnham, Alan, (2001). Mental Models and the Interpretation of Anaphora. Essays in Cognitive Psychology. Psychology Press. 
Garnham, Alan, Oakhill, Jane, (1990). Mental models as contexts for interpreting texts: implications from studies of anaphora. J. Semant. 7 (4), 379e393.

Goodman, N. D., \& Frank, M. C. (2016). Pragmatic Language Interpretation as Probabilistic Inference. Trends in Cognitive Sciences, 20 (11), 818 \{829. doi: 10.1016/j.tics.2016.08.005

Grice, P. (1975). Logic and conversation. In: Cole, P. and Morgan, J. (eds.) Syntax and semantics. 3: Speech acts. New York: Academic Press, pp.41-58.

Grodner, D., and Sedivy, J. C. (2011). The Effect of Speaker Specific Information on Pragmatic Inferences. In N. Pearlmutter and E. Gibson (eds.). The Processing and Acquisition of Reference (Vol. 2327, pp. 239-272). MIT Press.

Heller, D. (2020) The production and comprehension of referring expressions: Definite description. Language and Linguistics Compass. https://doi.org/10.1111/lnc3.12370

Heller, D., Grodner, D., and Tanenhaus, M. K. (2008). The role of perspective in identifying domains of reference. Cognition, 108(3), 831-836.

Johnson-Laird, Philip Nicholas, (1981). Comprehension as the construction of mental models. Phil. Trans. R. Soc. Lond. Ser. B Biol. Sci. 295, 353e374.

Johnson-Laird, Philip Nicholas, (1983). Mental Models: towards a Cognitive Science of Language, Inference, and Consciousness. Harvard University Press, Cambridge, MA.

Karmiloff-Smith, A. (1979). A Functional Approach to Child Language. Cambridge University Press.

Kuznetsova, A. et al. (2020). ImerTest: Tests in Linear Mixed Effects Models. R package version 3.12. https://cran.r-project.org/web/packages/lmerTest/

Levy, R. (2008). Expectation-based syntactic comprehension. Cognition, 106, 1126-1177. 10.1016/j.cognition.2007.05.006

Maes, A., Arts, A., and Noordman, L. (2004). Reference Management in Instructive Discourse. Discourse Processes: A Multidisciplinary Journal, 37 (2), 117\{144. doi: 10.1207/s15326950dp3702fng3

Mangold, R. and Pobel, R. (1988). Informativeness and Instrumentality in Referential communication. Journal of Language and Social Psychology. 7(3-4), pp.181-191.

Matuschek, H.; Kliegl, R.; Vasishth, S.; Baayen, R. H. \& Bates, D. (2017), Balancing Type I error and power in linear mixed models, Journal of Memory and Language, 94, 305-315.

Paraboni, I \& van Deemter, K. (2014) Reference and the facilitation of search in spatial domains. Language, Cognition and Neuroscience, 29:8, 10021017, doi: 10.1080/01690965.2013.805796

Paraboni, I. van Deemter, K. and Masthoff, J. (2007). Generating referring expressions: Making Referents easy to identify. Computational Linguistics. 33(2), 229-254.

Pechmann, T. (1984). Accentuation and Redundancy in Children and Adult's Referential Communication. In H. Bouma and D.G. Bouwhuis (eds.), Attention and Performance X: Control of Language Processes. NJ: Erlbaum. .

Pechmann, T. (1989). Incremental Speech Production and Referential Overspecification. Linguistics $27,1,89-110$. 
R Core Team (2020) R: A Language and Environment for Statistical Computing, version 3.6.3. R Foundation for Statistical Computing, Vienna.

Richardson, A. (2017) Does Relevance Guide Language Processing? An investigation into the effect of semantic and referential relevance on processing time. Unpublished undergraduate dissertation, University of Leeds.

Rubio-Fernández P. (2016). How Redundant Are Redundant Color Adjectives? An Efficiency-Based Analysis of Color Overspecification. Front. Psychol. 7:153. doi: 10.3389/fpsyg.2016.00153

Rubio-Fernandez, P. (2019). Overinformative speakers are cooperative: Revisiting the Gricean Maxim of Quantity. Cognitive Science 43 (11), e12797

Rubio-Fernandez, P. (under review), Color discriminability makes over-specification efficient: A reference production/ comprehension study.

Rubio-Fernandez, P., Mollica, F., \& Jara-Ettinger, J. (2021). Speakers and listeners exploit word order for communicative efficiency: A cross-linguistic investigation. Journal of Experimental Psychology: General, 150(3), 583-594. https://doi.org/10.1037/xge0000963

Rubio-Fernandez, P., Aparicio Terrasa, H., Shukla, V., and Jara-Ettinger, J. (under review). Contrastive inferences are sensitive to informativity expectations, adjective semantics and visual salience. Preprint at https://psyarxiv.com/mr4ah

Ryskin, R., Kurumada, C., and Brown-Schmidt, S. (2019). Information integration in modulation of pragmatic inferences during online language comprehension. Cognitive Science, 43(8), e12769.

Sedivy, J. (2003). Pragmatic versus form-based accounts of referential contrast: evidence for effects of informativity expectations. J. Psycholinguist. Res. 32, 3-23. doi: 10.1023/A:1021928914454

Sedivy, J., Tanenhaus, M., Chambers, C., and Carlson, G. (1999). Achieving incremental semantic interpretation through contextual representation. Cognition, 71, 109-147.

Sonnenschein, S. and Whitehurst, G. (1982). The effects of redundant communications on the behaviour of listeners: Does a picture need a thousand words? Journal of Psycholinguistic Research. 11(2), 115-125.

Sperber, D. and Wilson, D. (1986). Relevance: Communication and Cognition. Oxford: Blackwell. (Second edition 1995. Oxford: Blackwell.)

Sperber, D. Francesco, C. and Girotto, V. (1995). Relevance theory explains the selection task. Cognition, 57(1), 31-95.

SUBTLEX-UK: Subtitle-Based Word Frequencies for British English. [Online]. Accessed 18 June 2020. Available at: http://crr.ugent.be/archives/1423

Tanenhaus, M. Spivey-Knowlton, M. Eberhard, K. and Sedivy, J. (1995). Integration of Visual and Linguistic Information in Spoken Language Comprehension. Science, 268, 1632-1634.

van der Henst, J-P. Carles, L. and Sperber, D. 2002. Truthfulness and Relevance in Telling the Time. Mind and Language. 17(5), 457-466.

van der Sluis, I. and Krahmer, E. (2007). Generating Multimodal references. Discourse Processes. 44(3), 145-174. 
van Heuven, W. J. B., Mandera, P., Keuleers, E., \& Brysbaert, M. (2014). SUBTLEX-UK: A new and improved word frequency database for British English. The Quarterly Journal of Experimental Psychology, 67(6), 1176-1190. https://doi.org/10.1080/17470218.2013.85052

$\mathrm{Wu}, \mathrm{S}$. and Ma, Z. (2020). How is Chinese reading affected by under-specification and overspecification? Evidence from self-paced reading experiments. Journal of Pragmatics, 155, 213-233. https://doi.org/10.1016/j.pragma.2019.11.006.

\section{Appendix. Stimulus items}

\begin{tabular}{|c|c|}
\hline \multicolumn{2}{|c|}{ CRITICAL ITEMS } \\
\hline +semR1 & $\begin{array}{l}\text { In the room / there was a table. / The man helped his colleague move / the heavy table / } \\
\text { to the middle of the room. }\end{array}$ \\
\hline -semR1 & $\begin{array}{l}\text { In the room / there was a table. / The man helped his colleague sit at / the heavy table / } \\
\text { in the middle of the room. }\end{array}$ \\
\hline+ semR2 & $\begin{array}{l}\text { In the room / there were two tables. / The man helped his colleague move / the heavy } \\
\text { table / to the middle of the room. }\end{array}$ \\
\hline -semR2 & $\begin{array}{l}\text { In the room / there were two tables. / The man helped his colleague sit at / the heavy } \\
\text { table / in the middle of the room. }\end{array}$ \\
\hline+ semR1 & $\begin{array}{l}\text { There was a mirror / on the floor. / The girl stepped over / the broken mirror / when } \\
\text { she entered the room. }\end{array}$ \\
\hline -semR1 & $\begin{array}{l}\text { There was a mirror / on the floor. / The girl looked at / the broken mirror / when she } \\
\text { entered the room. }\end{array}$ \\
\hline$+\operatorname{semR} 2$ & $\begin{array}{l}\text { There were two mirrors / on the floor. / The girl stepped over / the broken mirror / } \\
\text { when she entered the room. }\end{array}$ \\
\hline -semR2 & $\begin{array}{l}\text { There were two mirrors / on the floor. / The girl looked at / the broken mirror / when } \\
\text { she entered the room. }\end{array}$ \\
\hline +semR1 & $\begin{array}{l}\text { There was a bird / at the side of the garden. / Sarah listened to / the noisy bird / all day } \\
\text { long. }\end{array}$ \\
\hline -semR1 & $\begin{array}{l}\text { There was a bird / at the side of the garden. / Sarah painted / the noisy bird / all day } \\
\text { long. }\end{array}$ \\
\hline+ semR2 & $\begin{array}{l}\text { There were two birds / at the side of the garden. / Sarah listened to / the noisy bird / all } \\
\text { day long. }\end{array}$ \\
\hline -semR2 & $\begin{array}{l}\text { There was two birds / at the side of the garden. / Sarah painted / the noisy bird / all day } \\
\text { long. }\end{array}$ \\
\hline+ semR1 & $\begin{array}{l}\text { The rabbit was waiting / in the kitchen. / Bob fed / the hungry rabbit / when he got } \\
\text { home. }\end{array}$ \\
\hline -semR1 & $\begin{array}{l}\text { The rabbit was waiting / in the kitchen. / Bob tickled / the hungry rabbit / when he got } \\
\text { home. }\end{array}$ \\
\hline+ semR2 & $\begin{array}{l}\text { The rabbits were waiting / in the kitchen. / Bob fed / the hungry rabbit / when he got } \\
\text { home. }\end{array}$ \\
\hline -semR2 & $\begin{array}{l}\text { The rabbits were waiting / in the kitchen. / Bob tickled / the hungry rabbit / when he } \\
\text { got home. }\end{array}$ \\
\hline+ semR1 & $\begin{array}{l}\text { The parents bought / a chandelier. / Their friends helped them lift / the large chandelier } \\
\text { / in the shop. }\end{array}$ \\
\hline
\end{tabular}




\begin{tabular}{|c|c|}
\hline -semR1 & $\begin{array}{l}\text { The parents bought / a chandelier. / Their friends helped them choose / the large } \\
\text { chandelier / from the shop. }\end{array}$ \\
\hline$+\operatorname{semR} 2$ & $\begin{array}{l}\text { The parents bought / two chandeliers. / Their friends helped them lift / the large } \\
\text { chandelier / in the shop. }\end{array}$ \\
\hline -semR2 & $\begin{array}{l}\text { The parents bought / two chandeliers. / Their friends helped them choose / the large } \\
\text { chandelier / in the shop. }\end{array}$ \\
\hline +semR1 & Gregg took a bite / from an apple. / He spat out / the mouldy apple / straight away. \\
\hline -semR1 & Gregg took a bite / from an apple. / He chewed / the mouldy apple / straight away. \\
\hline+ semR2 & Gregg took a bite / from two apples. / He spat out / the mouldy apple / straight away. \\
\hline -semR2 & Gregg took a bite / from two apples. / He chewed / the mouldy apple / straight away. \\
\hline$+\operatorname{semR} 1$ & $\begin{array}{l}\text { There was a scarf / on the chair. / Josie put on / the warm scarf / before leaving the } \\
\text { house. }\end{array}$ \\
\hline -semR1 & $\begin{array}{l}\text { There was a scarf / on the chair. / Josie moved / the warm scarf / before leaving the } \\
\text { house. }\end{array}$ \\
\hline+ semR2 & $\begin{array}{l}\text { There were two scarves / on the chair. / Josie put on / the warm scarf / before leaving } \\
\text { the house. }\end{array}$ \\
\hline -semR2 & $\begin{array}{l}\text { There were two scarves / on the chair. / Josie moved / the warm scarf / before leaving } \\
\text { the house. }\end{array}$ \\
\hline$+\operatorname{semR} 1$ & $\begin{array}{l}\text { There was a bowl of food / next to the fridge. / The cat ate / the tasty food / before } \\
\text { having a nap. }\end{array}$ \\
\hline -semR1 & $\begin{array}{l}\text { There was a bowl of food / next to the fridge. / The cat smelled / the tasty food / before } \\
\text { having a nap. }\end{array}$ \\
\hline$+\operatorname{semR2}$ & $\begin{array}{l}\text { There were two bowls of food / next to the fridge. / The cat ate / the tasty food / before } \\
\text { having a nap. }\end{array}$ \\
\hline -semR2 & $\begin{array}{l}\text { There were two bowls of food / next to the fridge. / The cat smelled / the tasty food / } \\
\text { before having a nap. }\end{array}$ \\
\hline+ semR1 & $\begin{array}{l}\text { Florence noticed a bag / on the shop floor. / She bought / the pretty bag / and left the } \\
\text { store. }\end{array}$ \\
\hline -semR1 & $\begin{array}{l}\text { Florence noticed a bag / on the shop floor. / She moved / the pretty bag / and left the } \\
\text { store. }\end{array}$ \\
\hline$+\operatorname{semR2}$ & $\begin{array}{l}\text { Florence noticed two bags / on the shop floor. / She bought / the pretty bag / and left } \\
\text { the store. }\end{array}$ \\
\hline -semR2 & $\begin{array}{l}\text { Florence noticed two bags / on the shop floor. / She moved / the pretty bag / and left } \\
\text { the store. }\end{array}$ \\
\hline+ semR1 & $\begin{array}{l}\text { There was a spider / on Penny's book. / She screamed at / the scary spider / for a long } \\
\text { time. }\end{array}$ \\
\hline -semR1 & There was a spider / on Penny's book. / She stroked / the scary spider / for a long time. \\
\hline$+\operatorname{semR2}$ & $\begin{array}{l}\text { There were two spiders / on Penny's book. / She screamed at / the scary spider / for a } \\
\text { long time. }\end{array}$ \\
\hline -semR2 & $\begin{array}{l}\text { There were two spiders / on Penny's book. / She stroked / the scary spider / for a long } \\
\text { time. }\end{array}$ \\
\hline$+\operatorname{semR} 1$ & $\begin{array}{l}\text { Jack bought a trampoline / early that morning. / His dog jumped on / the bouncy } \\
\text { trampoline / before his walk. }\end{array}$ \\
\hline
\end{tabular}




\begin{tabular}{|l|l|}
\hline -semR1 & $\begin{array}{l}\text { Jack bought a trampoline / early that morning. / His dog looked at / the bouncy } \\
\text { trampoline / before his walk. }\end{array}$ \\
\hline +semR2 & $\begin{array}{l}\text { Jack bought two trampolines / early that morning. / His dog jumped on / the bouncy } \\
\text { trampoline / before his walk. }\end{array}$ \\
\hline -semR2 & $\begin{array}{l}\text { Jack bought two trampolines / early that morning. / His dog looked at / the bouncy } \\
\text { trampoline / before his walk. }\end{array}$ \\
\hline+ semR1 & $\begin{array}{l}\text { Susanne bought herself / a new painting. / She dropped / the weighty painting / in the } \\
\text { living room. }\end{array}$ \\
\hline -semR1 & $\begin{array}{l}\text { Susanne bought herself / a new painting. / She displayed / the weighty painting / in the } \\
\text { living room. }\end{array}$ \\
\hline+ semR2 & $\begin{array}{l}\text { Susanne bought herself / two new paintings. / She dropped / the weighty painting / in } \\
\text { the living room. }\end{array}$ \\
\hline -semR2 & $\begin{array}{l}\text { Susanne bought herself / two new paintings. / She displayed / the weighty painting / in } \\
\text { the living room. }\end{array}$ \\
\hline
\end{tabular}

\begin{tabular}{|c|c|}
\hline \multicolumn{2}{|c|}{ FILLER ITEMS } \\
\hline 1 & Sarah didn't feel well. / She had to miss / a day of work. \\
\hline 2 & The package was delivered / a week early. / Harry was ecstatic. \\
\hline 3 & The university was / extremely cold. / The heating wasn't working / all day. \\
\hline 4 & She drank coffee / every day. / Her doctor said / she should stop. \\
\hline 5 & Ben has started / constructing the kitchen. / He is already / regretting his decision. \\
\hline 6 & The coat was long and fluffy. / Lisa thought that / it would be perfect / for winter. \\
\hline 7 & Ted never wanted / to be a chef. / When he was younger, / he wanted to be / a doctor. \\
\hline 8 & Jess is a qualified dentist. / She has recently decided / to pursue psychology instead. \\
\hline 9 & Amy and Wendy are inseparable. / Unfortunately, / Wendy is moving / to California. \\
\hline 10 & $\begin{array}{l}\text { The shoes were covered / in silver and gold glitter. / They were the most expensive pair / in } \\
\text { the whole shop. }\end{array}$ \\
\hline 11 & $\begin{array}{l}\text { George and Martin are vegetarians. / Jim finds this frustrating / when he makes dinner for } \\
\text { them. }\end{array}$ \\
\hline 12 & $\begin{array}{l}\text { The kids left the door open overnight. / They were in a lot of trouble / when their parents got } \\
\text { home / the following day. }\end{array}$ \\
\hline 13 & The shop was filled / with dolls and toys. / Sally felt like / she was in heaven. \\
\hline 14 & Gill tells his brother everything. / He always calls him / when he is sad. \\
\hline 15 & The sun was shining brightly. / It was too hot / for Nina to concentrate. \\
\hline 16 & The woman left the meeting / in a hurry. / She was too frustrated / to stay any longer. \\
\hline 17 & Alan found / an ill puppy. / He took the puppy home / and looked after him. \\
\hline 18 & $\begin{array}{l}\text { Diana grew up in Northern Ireland, / but always wanted / to live in the city. / She moved to } \\
\text { London / as soon as she could. }\end{array}$ \\
\hline 19 & Kevin has always / enjoyed astrophysics. / He loves that his children / share his passion. \\
\hline
\end{tabular}




\begin{tabular}{|c|c|}
\hline 20 & $\begin{array}{l}\text { Beth didn't make friends easily. / However, / when she went to University / she met many } \\
\text { people / similar to her. }\end{array}$ \\
\hline 21 & Millie failed her exams. / She worked extremely hard / and passed all of her retakes. \\
\hline 22 & Henrietta didn't know / what to do in life. / She decided to travel / and decide later. \\
\hline 23 & There was a car / in the driveway. / A boy threw a rock / at the car / and ran away. \\
\hline 24 & The old woman liked / to read in her local café. / She could spend hours / in there every day. \\
\hline 25 & Ben enjoys swimming. / He hopes / to save enough money / to buy a pool. \\
\hline 26 & The house was / very old. / You could hear noises / throughout the night. \\
\hline 27 & Nicola didn't want / to see her boss. / She called in sick / so that she could / avoid her. \\
\hline 28 & There was a lot of traffic. / The two hour journey / should have only taken / thirty minutes. \\
\hline 29 & It was a very stormy night. / When Beth woke up, / the tree in her garden / had fallen down. \\
\hline 30 & Robyn always wants / to go on holiday. / She hates staying in England / for too long. \\
\hline 31 & The baby cried all night. / Sully didn't get any sleep / then had to go to work / the next day. \\
\hline 32 & $\begin{array}{l}\text { Ella hated Christmas. / John always tried / to get her in the holiday spirit / but it never } \\
\text { worked. }\end{array}$ \\
\hline 33 & Thomas won the lottery. / The first thing he did was / book a one-way ticket / to Las Vegas. \\
\hline 34 & $\begin{array}{l}\text { The barista made the coffee / far too strong. / He was knew to his job / and still had / a lot to } \\
\text { learn. }\end{array}$ \\
\hline 35 & Lily was proud / of her work. / She was shocked when / all she got was / fifty percent. \\
\hline 36 & $\begin{array}{l}\text { The parents told their children / that they would be moving house. / The kids took the news / } \\
\text { surprisingly well. }\end{array}$ \\
\hline 37 & $\begin{array}{l}\text { The boy loved / visiting his grandparents. / They always let him / eat as many sweets / as he } \\
\text { wanted. }\end{array}$ \\
\hline 38 & David had too much work / and too little time. / He decided / to pay his friends / to help him. \\
\hline 39 & The policeman banged / on the door. / He waited five minutes / before knocking it down. \\
\hline 40 & $\begin{array}{l}\text { Hattie decided / to stop drinking. / No-one believed she could do it / but she proved everyone } \\
\text { wrong. }\end{array}$ \\
\hline 41 & The phone started ringing. / Neal pretended not to hear it / so that his wife / would answer it. \\
\hline 42 & $\begin{array}{l}\text { Larry had two pet butterflies. / He loved to watch them / fly round his room / for hours on } \\
\text { end. }\end{array}$ \\
\hline 43 & $\begin{array}{l}\text { Lenny always wanted / to go travelling. / Unfortunately, / his fear of flying / has made this } \\
\text { problematic. }\end{array}$ \\
\hline 44 & $\begin{array}{l}\text { The group decided / to go on a boat trip. / They were amazed when / they saw several } \\
\text { dolphins. }\end{array}$ \\
\hline 45 & $\begin{array}{l}\text { Rory was excited / to go to the zoo. / He had been asking his parents / if they could go / for } \\
\text { months. }\end{array}$ \\
\hline 46 & Matt fell asleep / on the beach. / When he awoke, / he realised that / he had been badly burnt. \\
\hline 47 & $\begin{array}{l}\text { The mountains surrounded / the village. / They were always most beautiful / in the winter } \\
\text { months. }\end{array}$ \\
\hline 48 & $\begin{array}{l}\text { Suzanne felt lonely / when she first moved to England. / Luckily, / she found friends / after } \\
\text { joining a book club. }\end{array}$ \\
\hline 49 & $\begin{array}{l}\text { Everyone in the class / was excited for graduation. / It was the first year / that no-one had } \\
\text { failed. }\end{array}$ \\
\hline 50 & Naomi made a speech / at the wedding. / By the end, / everyone was in tears. \\
\hline
\end{tabular}




\begin{tabular}{|c|c|}
\hline 51 & $\begin{array}{l}\text { Carl loved to read. / He would often cancel / on his friends / so that he could / finish his } \\
\text { book. }\end{array}$ \\
\hline 52 & $\begin{array}{l}\text { The young boy was looking forward / to his birthday. / He always loved / the presents he } \\
\text { received / from his family. }\end{array}$ \\
\hline 53 & $\begin{array}{l}\text { Oscar's favourite band / are playing at his local pub / this weekend. / He has convinced his } \\
\text { friends / to go with him. }\end{array}$ \\
\hline 54 & $\begin{array}{l}\text { The new couple / are buying a flat together. / Their friends and family think / that they are } \\
\text { going too fast. }\end{array}$ \\
\hline 55 & The vase was / very special to Winston. / He was furious / when his son broke it. \\
\hline 56 & Every Monday, / Lisa decided / to start her diet. / Every Tuesday, / she gave up. \\
\hline 57 & $\begin{array}{l}\text { The kids snuck / onto the bus / without paying. / The driver kicked them off / when he } \\
\text { realised. }\end{array}$ \\
\hline 58 & The mouse was hiding / under the sofa. / It ran away / when it saw the cat. \\
\hline 59 & $\begin{array}{l}\text { The new headmaster / made many improvements / at the school. / He was very popular / with } \\
\text { the staff. }\end{array}$ \\
\hline 60 & Billy always struggled / with Maths. / He only ever wanted / to be a writer. \\
\hline 61 & Liv found / a ten pound note. / She decided / to buy a round of drinks / for her friends. \\
\hline 62 & $\begin{array}{l}\text { Peggy baked a cake / for her family. / She didn't know that / they only pretend / to like her } \\
\text { food. }\end{array}$ \\
\hline 63 & It was a very windy day. / Yasmin's hat flew / off her head / as soon as she left / the house. \\
\hline 64 & Fred bought three pens / to the exam. / He realised very quickly / that none of them worked. \\
\hline 65 & Julia was finding her job / very stressful. / She considered starting / her own company. \\
\hline 66 & $\begin{array}{l}\text { Joseph put his alarm clock / at the other end / of the room. / This forced him / to get up in the } \\
\text { morning. }\end{array}$ \\
\hline 67 & $\begin{array}{l}\text { Phoebe started writing a book. / She didn't know / where to begin, / so started writing about / } \\
\text { her own experiences. }\end{array}$ \\
\hline 68 & The glass was shattered / all over the floor. / Richard cut his foot / very badly. \\
\hline 69 & $\begin{array}{l}\text { Zara was always cold. / In January, / she started wearing her coat / when she was / in the } \\
\text { house. }\end{array}$ \\
\hline 70 & $\begin{array}{l}\text { The manager was very approachable. / She wanted her employees / to be able to talk to her / } \\
\text { about their problems. }\end{array}$ \\
\hline 71 & The plant was dying. / It hadn’t been watered / in two weeks. \\
\hline 72 & $\begin{array}{l}\text { Frankie was a vegetarian. / She didn't realise / that the salad contained chicken / until after / } \\
\text { she had finished. }\end{array}$ \\
\hline
\end{tabular}

\begin{tabular}{|l|l|l|}
\hline & $\begin{array}{l}\text { ATTENTION } \\
\text { MONITORING } \\
\text { QUESTIONS }\end{array}$ & \\
\hline $\begin{array}{l}\text { (Kevin always enjoyed astrophysics. He loves that his } \\
\text { children share his passion.) }\end{array}$ & Does Kevin have children? & yes \\
\hline $\begin{array}{l}\text { (The house was very old. You could hear noises throughout } \\
\text { the night.) }\end{array}$ & Was the house old? & yes \\
\hline
\end{tabular}




\begin{tabular}{|l|l|l|}
\hline $\begin{array}{l}\text { (The old woman liked to read in her local cafe. She could } \\
\text { spend hours in there every day.) }\end{array}$ & $\begin{array}{l}\text { Does the old woman read in } \\
\text { her local pub? }\end{array}$ & no \\
\hline $\begin{array}{l}\text { (Robyn always wants to go on holiday. She hates staying in } \\
\text { England for too long.) }\end{array}$ & $\begin{array}{l}\text { Does Robyn like staying in } \\
\text { England? }\end{array}$ & no \\
\hline $\begin{array}{l}\text { (Diana grew up in Northern Ireland but always wanted to live } \\
\text { in the city. She moved to London as soon as she could.) }\end{array}$ & $\begin{array}{l}\text { Did Diana move to } \\
\text { London? }\end{array}$ & yes \\
\hline $\begin{array}{l}\text { (Gill tells his brother everything. He always calls him when } \\
\text { he is sad.) }\end{array}$ & $\begin{array}{l}\text { Does Gill call his sister } \\
\text { when he is sad? }\end{array}$ & no \\
\hline $\begin{array}{l}\text { (The woman left the meeting early. She was too frustrated to } \\
\text { stay any longer.) }\end{array}$ & $\begin{array}{l}\text { Did the woman enjoy the } \\
\text { meeting? }\end{array}$ & no \\
\hline $\begin{array}{l}\text { (Ben enjoys swimming. He hopes to save enough money to } \\
\text { buy a pool.) }\end{array}$ & Does Ben like swimming? & yes \\
\hline $\begin{array}{l}\text { (There was a lot of traffic. The two hour journey should have } \\
\text { only taken thirty minutes.) }\end{array}$ & $\begin{array}{l}\text { Did the journey take thirty } \\
\text { minutes? }\end{array}$ & no \\
\hline (The plant was dying. It hadn't been watered in two weeks.) & $\begin{array}{l}\text { Was the plant recently } \\
\text { watered? }\end{array}$ & no \\
\hline
\end{tabular}

\begin{tabular}{|l|l|}
\hline \multicolumn{2}{|l|}{ PRACTICE ITEMS } \\
\hline 1 & Amy bought / a brand new jacket. / She wore the jacket / every day. \\
\hline 2 & Jack showed his wife / a photo. / She said / that she didn't like it. \\
\hline 3 & Colin was offered / the teaching job in Japan. / He is leaving / in one month. \\
\hline $\begin{array}{l}\text { PRACTICE } \\
\text { QUESTION }\end{array}$ & $\begin{array}{l}\text { Was the teaching job in China? } \\
\text { texting him. }\end{array}$ \\
\hline 4 & $\begin{array}{l}\text { Karla always said / that she would never / go travelling. / She is now living / in the } \\
\text { south of Australia. }\end{array}$ \\
\hline 5 & $\begin{array}{l}\text { George's parents were very strict. / They never let him / stay out late / with his } \\
\text { friends. }\end{array}$ \\
\hline 6 & $\begin{array}{l}\text { Belinda had been hoping / for nice weather. / She was disappointed / when she woke } \\
\text { up to rain. }\end{array}$ \\
\hline 7 &
\end{tabular}

